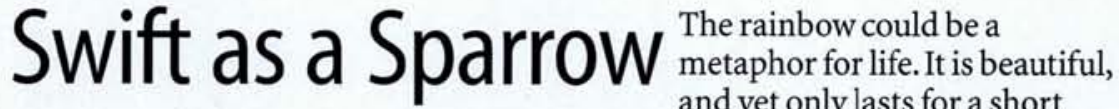

time. We understand it, by projecting light rays through raindrops, and yet not grasp it physically. Perhaps (wonders a dreamy editor) a comet could be a similar metaphor. For the visit of a comet to the region of the solar system close to the Earth and the Sun is a fleeting one. Its appearance, like life, is short. We can try to understand it, by probing its tail and interior, and perhaps then be offered a glimpse of the origins of things. Admittedly, it doesn't have the colour of a rainbow, but the thought of it on its long journey in the cold of the outer reaches of the solar system, before and after its appearance to us, is awe-provoking. The metaphor is not unlike one thought up by a British saint some 1267 years ago. The Venerable Bede, belatedly canonised but still known by his lesser title, wrote a book called Historia Ecclesiastica gentis Anglorum around $731 \mathrm{AD}$. It contains a moving passage which is addressed to a non-Christian English King.

"'Such,' he said,'O king, seems to me the present life of men on Earth, in comparison with that time which to us is uncertain, as if when on a winter's night you sit feasting with your officers and landowners, a single sparrow should fly swiftly into the hall, and coming in at one door flies instantly out through another. In that time in which it is indoors it is not touched by the fury of the winter, but then, this smallest space of calmness being passed almost in a flash, from winter going into winter again,it is lost to your eyes. Somewhat like that appears the life of man, but of what follows or what went before, we are utterly ignorant."

Bede is describing the spiritual loneliness of people (which he thought Christian faith could alleviate). He uses the cold of winter not just to describe, but to make us feel the unknown. And you can easily imagine a small bird, fragile and perhaps uncertain, flying past the warm glow of an 8th century hearth.

It is no wonder that the human condition can be upset by events that happen all too quickly-our time next to the hearth is short lived enough to make us feel we need to get things right quickly. And all too quickly can physics find itself flying past the warm glow of media attention, as the recent flight through the media of comet 1997 XF11 showed. This comet-devil you may remember (and if the memory has faded it only further illustrates the transience of the event) was projected to fly uncomfortably close to the Earth in the year 2028, and flew straight onto front pages of newspapers and magazines around the world. But a careful assessment of the data the very next day turned its trajectory away from a collision course (the first assessment was not in error, it was lacking in precision).

To see media anxiety rise and fall so quickly, must be hard on the emotions of scientists who live with asteroids day in and day out. Even if it's not, it must have been a little bit annoying to those who seek funding for near-Earth asteroid studies, and for those who have asked for more attention to be paid to them, for the media to suddenly switch, as they did, to "there's no need to worry" headlines.

Who can tell what is in public minds now? Are people aware of the danger from asteroids? Or on a simpler level, do more people now know what an asteroid is? (Which would be a good thing). We should understand more about the media, its needs and effects. For it is a glow by which space scientists (and others) can hope to warm-up funding for their studies. NASA has a team of experts who stoke the media hearth when necessary. Although, as Swiss space scientist Hans Balsiger pointed out to this editor recently, they managed to keep the media alight during last year's Mars landing only while there were pictures to behold. As in everything: enjoy things while they last.

\section{Three Ps} The changing world of publishing, and of communication in general, involves the three Ps: public, private and professional bodies. We need both the commercial logic of businessmen and the long-term commitment of learned societies for effective, stable journals (whether electronic or not). Just how the balance and cooperation should be best managed is a topic of discussion everywhere in Europe today, as the scientific publishing industry becomes more volatile. One development is the rapid growth of physics Websites. The most successful one, Tiptop, created two years ago by three postdocs, is to be sold to a publisher soon. A good thing? A bad thing? Let us know.

\section{European Physical Society}

EPS Secretariat, BP 2136

F-68060 Mulhouse Cedex, France

phone $+33389329440 ;$ fax +33389329449

The EPS counts among its members some 3400 Individual Ordinary Members and 72,000 National Society Members who belong to 36 national physical societies across Europe.

\section{Managing Editor}

Toby Chapman

email eneditor@univ-mulhouse.fr

\section{Subscriptions}

ISSN print edition 0531-7479

ISSN electronic edition 1432-1092

Volume 29: 6 issues will appear in 1998. Recommended annual subscription prices, institutions DM 228; individuals DM 98. Special rate for new individual subscribers DM 78 for one year. All prices plus carriage. EPS Individual Ordinary Members receive Europhysics News free of charge. Members of EPS National Member Societies, except the German Physical Society and the Institute of Physics, UK, receive Europhysics News through their society. Subscriptions can either be placed via an agent or sent directly to Springer-Verlag, Postfach 3113 40, D-10643 Berlin, Germany phone $+493082787358 ; f a x+493082787448$ email subscriptions@springer.de Cancellation must be received by 30 September to take effect the following year.

\section{Electronic edition}

An electronic edition of this magazine is available via the LINK Information Service, available online at link.springer.de. You can automatically receive by email the table of contents with direct links to the respective abstracts as soon as an issue is available online. For free registration and further information go to link.springer.de.alert.

Alternatively, you may contact us by email access@link.springer.de,or

fax +496221487288

\section{Production}

Springer-Verlag

3051 - Journal Production Department Lenore Grenzdörfer, Heidelberger Platz 3 D-14197 Berlin, Germany

phone +4930 827 87 750; fax +493082787440 email grenzdoerfer@springer.de

\section{Advertisements}

\section{Springer Verlag}

E. Lückermann, S. Kindt, Springer-Verlag, Postfach 3113 40, D-14197 Berlin, Germany phone +493082787741 ; fax +493082787300 email anzeigen@springer.de

Advertising is charged according to space and position pro rata, based on DM 4000 for a full page, black and white. Rates on request. Discounts for EPS Associate Members. Deadline for orders: on request (normally four weeks before publication).

\section{Printer}

Universitätsdruckerei H.Stürtz AG, Würzburg 